\title{
Article \\ Low-Temperature and Additive-Free Synthesis of Spherical MIL-101(Cr) with Enhanced Dye Adsorption Performance
}

\author{
Tian Zhao *D, Hexin Zhu, Ming Dong, Minmin Zou, Songfan Tang, Mingliang Luo and Xianggang Li * \\ School of Packaging and Materials Engineering, Hunan University of Technology, Zhuzhou 412007, China; \\ zhx19a@126.com (H.Z.); dongming666@126.com (M.D.); zz09181002@163.com (M.Z.); \\ m15279857328@163.com (S.T.); westbrook123666@163.com (M.L.) \\ * Correspondence: tian_zhao@hut.edu.cn (T.Z.); lixianggang@hut.edu.cn (X.L.)
}

\begin{abstract}
The chromium-benzenedicarboxylate metal-organic framework (MOF), MIL-101(Cr), is one of the most well-investigated and widely used prototypical MOFs. Regarding its synthesis, the use of a toxic modulator (usually HF) and high reaction temperature $\left(220^{\circ} \mathrm{C}\right)$ are the main factors hindering its further expansion of production and utilization. In fact, high quality MIL-101(Cr) crystals can be prepared at a much lower temperature $\left(160^{\circ} \mathrm{C}\right)$ with spherical morphology via an additive-free approach. Compared to traditional octahedral MIL-101(Cr), the spherical MIL-101(Cr) possesses higher adsorption performance toward dye molecules, including methyl orange $(\mathrm{MO})$ and rhodamine $\mathrm{B}(\mathrm{RB})$. The results suggest that toxic additives and high reaction temperatures are not essential in the synthesis of MIL-101(Cr), and the fabrication of spherical MIL-101(Cr) may offer a facile and effective pathway for the large-scale industrial application of MIL-101(Cr).
\end{abstract}

Keywords: spherical MIL-101(Cr); morphology control; dye adsorption; industrial application

check for

updates

Citation: Zhao, T.; Zhu, H.; Dong, M.; Zou, M.; Tang, S.; Luo, M.; Li, X. Low-Temperature and Additive-Free Synthesis of Spherical MIL-101(Cr) with Enhanced Dye Adsorption Performance. Inorganics 2022, 10, 33. https://doi.org/10.3390/ inorganics 10030033

Academic Editor: Koichiro Takao

Received: 9 February 2022

Accepted: 28 February 2022

Published: 4 March 2022

Publisher's Note: MDPI stays neutral with regard to jurisdictional claims in published maps and institutional affiliations.

Copyright: (C) 2022 by the authors. Licensee MDPI, Basel, Switzerland. This article is an open access article distributed under the terms and conditions of the Creative Commons Attribution (CC BY) license (https:// creativecommons.org/licenses/by/ $4.0 /)$

\section{Introduction}

Metal-organic frameworks (MOFs) are a kind of three-dimensional porous crystalline material which are formed by metal ions or metal clusters with organic ligands [1,2]. Compared to traditional porous crystalline materials, MOFs have the characteristics of high specific surface area [3], large porosity [4], and good chemical/thermal stability [5]. In addition, most MOFs have the advantages of mild reaction conditions, simple synthesis approaches, and easy availability of raw materials. Therefore, MOFs have broader application prospects than traditional porous materials, such as gas storage/separation [6,7], energy storage/conversion [8,9], drug delivery [10,11], catalysis [12,13], fluorescence [14,15], magnetic [16], clinical diagnosis [17], chemical sensors [18], etc.

MIL-101(Cr) is one of the most representative porous materials among chromiumbased MOFs. It has a high pore volume, large specific surface area, and excellent chemical/water stability, with an empirical formula $\left[\mathrm{Cr}_{3}(\mathrm{O}) \mathrm{X}(\mathrm{BDC})_{3}\left(\mathrm{H}_{2} \mathrm{O}\right)_{2}\right]$ (where BDC is terephthalic acid and $\mathrm{X}$ is $\mathrm{OH}^{-}$or $\mathrm{F}^{-}$) [19]. Its structure is similar to MTN zeolite topology by the coordination of $\mathrm{Cr}_{3} \mathrm{O}$ ion clusters and terephthalate (BDC $\left.{ }^{2-}\right)$. MIL-101(Cr) has two types of mesoporous cage cavities with diameters of $29 \AA$ and $34 \AA$ (Figure S1), separately, and the max aperture window can reach $16 \AA$, with a high specific BET surface area of $4100 \mathrm{~m}^{2} \mathrm{~g}^{-1}$. The terminal connected water molecules of MIL-101(Cr) can be removed under high temperature or vacuum conditions, which creates potential Lewis acid sites [20]. Hence, MIL-101(Cr) demonstrates quite good water stability, which makes it suitable for wide applications, especially in the presence of moisture/water conditions, such as catalysis $[21,22]$, adsorption $[23,24]$, separation [25,26], drug delivery [27,28], gas storage [29,30], water pollution treatment [31], and mixed matrix membranes [32,33], among others.

The traditional synthesis of MIL-101(Cr) reports an additive-free route, but also the adding of an equimolar amount of hydrofluoric acid (HF) to $\mathrm{Cr}^{3+}$ and $\mathrm{H}_{2} \mathrm{BDC}$, and the products are isostructural [19]. The HF route shows better crystallinity and porosity for 
the products; thus, most of the other groups follow the HF approach to synthesize MIL$101(\mathrm{Cr})$ [19,34-37]. However, both of the above reaction routes occur at $220^{\circ} \mathrm{C}$, the yield are relatively low $(\sim 50 \%)$, and the added $\mathrm{HF}$ is a chemical toxicant, which are not advantageous for large-scale industrial syntheses [38]. Thus, the price of high-quality commercial MIL$101(\mathrm{Cr})$ products can reach over $570 \$ / \mathrm{g}$, which is much higher than other commonly used MOFs (such as ZIFs, UiOs, HKUST-1, etc.). The detailed price list is shown in Table S1.

In the previous study, most of the researchers followed the HF route to prepare MIL101(Cr) by Férey et al. [19]. Apart from HF, the researchers also tried to use other modulators to replace HF in MIL-101(Cr) synthesis, including acetic acid, nitric acid, hydrochloric acid, sulfuric acid, sodium hydroxide, benzoic acid, sodium acetate, tetramethylammonium hydroxide, etc. [36,39-44] (see details in Table S2). Nevertheless, all these procedures still need extra additives, conducted at high temperature, and contain tedious purification processes. Conversely, the study of additive-free synthesis for MIL-101(Cr) is ignored, because of its low crystallinity and low BET surface area in the original report by Férey et al. [19].

Herein, we carefully investigated the fluorine-free route of MIL-101(Cr) synthesis via hydrothermal reaction at various temperatures $\left(220-160^{\circ} \mathrm{C}\right)$. The results showed that high-quality MIL-101(Cr) products also can be prepared at temperatures as low as $160{ }^{\circ} \mathrm{C}$ with spherical morphology, which possessed high specific BET surface area $\left(3021 \mathrm{~m}^{2} \mathrm{~g}^{-1}\right)$ and quite good yield (>52\%). More importantly, among all samples, spherical MIL-101(Cr) exhibited the highest adsorption capacity toward dyes MO and Rhodamine B (RB), with maximum uptakes of $444.3 \mathrm{mg} \mathrm{g}^{-1}$ and $230.3 \mathrm{mg} \mathrm{g}^{-1}$, respectively.

\section{Experimental}

\subsection{Materials and Reagents}

$\mathrm{Cr}\left(\mathrm{NO}_{3}\right)_{3} \cdot 9 \mathrm{H}_{2} \mathrm{O}(99.5 \%, \mathrm{AR})$ and terephthalate $\left(\mathrm{H}_{2} \mathrm{BDC}, 99 \%\right.$, $\left.\mathrm{AR}\right)$, were bought from Aladdin Chemical Reagent Co., Ltd. (Shanghai, China). N,N-Dimethylformamide (DMF, 99.5\%, AR), and Ethanol (99.7\%, AR) was acquired from Sinopharm Chemical Reagent Co., Ltd. (Shanghai, China).

\subsection{Additive-Free Synthesis of MIL-101(Cr)}

MIL-101(Cr) was synthesized by hydrothermal method. Typically, $\mathrm{Cr}\left(\mathrm{NO}_{3}\right) 3 \cdot 9 \mathrm{H}_{2} \mathrm{O}$ $(0.8 \mathrm{~g})$ and H2BDC $(0.332 \mathrm{~g})$ were dissolved in distillated water $(10 \mathrm{~mL})$ and stirred for $30 \mathrm{~min}$. Then the mixture was placed in a $25 \mathrm{~mL}$ autoclave and heated at different temperatures $\left(220-160^{\circ} \mathrm{C}\right)$ for $8 \mathrm{~h}$. When the reaction was complete, the autoclave was cooled down to room temperature naturally. The green solids were collected and washed with DMF and ethanol twice $(8 \mathrm{~h})$ with stirring. The final products were dried under vacuum at $120^{\circ} \mathrm{C}$ for $2 \mathrm{~h}$ and labeled as 220-MIL-101, 200-MIL-101, 180-MIL-101, and 160-MIL-101 separately (the numbers stand for the reaction temperatures).

\subsection{Characterization}

The micromorphologies of the samples were characterized using Zeiss Gemini 300 scanning electron microscopy. Transmission electron microscopy (TEM) was performed on an FEI Talos F200X electron microscope. The BET specific surface areas of the samples were measured with $\mathrm{N}_{2}$ adsorption isotherms on a specific surface analyzer (NOVA-4200e, Quantachrome, Boynton Beach, FL, USA). X-ray diffraction (XRD) measurements were performed using a Bruker D8 Advance X-ray diffractometer with $\mathrm{CuK} \alpha$ radiation $(\lambda=1.5418 \AA)$, operating at $30 \mathrm{kV}$, with a scanning speed of $2\left(^{\circ}\right) / \mathrm{min}$ and a scanning range of $5-50^{\circ}$. Dye concentrations of the test samples were obtained by UV-vis spectrophotometer (UV-2600, Shimadzu, Kyoto, Japan).

\subsection{Dye Adsorption Experiment}

The adsorption capacities of the products were assessed by MO and RB. Dye adsorption experiments were conducted by adding $5 \mathrm{mg}$ of adsorbent into $10 \mathrm{~mL}$ of different initial concentrations of dye solutions at room temperature (298 K). 
The concentrations of remaining $\mathrm{MO}$ and $\mathrm{RB}$ in the solution were explored using a UV-vis spectrophotometer at wavelengths of 300 and $700 \mathrm{~nm}$, separately. The amount of adsorbent to dye $\left(q_{e}, \mathrm{mg} \mathrm{g}^{-1}\right)$ was calculated according to Equation (1) [45]

$$
q_{e}=\frac{\left(C_{0}-C_{e}\right) V}{m}
$$

where $C_{0}$ is the original concentration of the dye $\left(\mathrm{mg} \mathrm{L}^{-1}\right), C_{e}$ is the remaining concentration of the dye $\left(\mathrm{mg} \mathrm{L}^{-1}\right), V$ is the volume of the dye solution $(\mathrm{L})$, and $m(\mathrm{~g})$ is the mass of the adsorbent.

\subsection{Adsorption Kinetic Model}

To investigate the process of dye adsorption by the adsorbent, pseudo-first-order and pseudo-second-order kinetic models were adopted to fit the adsorption data [46,47], respectively. The linear expressions of the pseudo-first-order kinetic equation and the pseudo-second-order kinetic equation were shown in Equations (2) and (3) $[48,49]$

$$
\begin{gathered}
\ln \left(q_{e}-q_{t}\right)=\ln q_{e}-k_{1} t \\
\frac{t}{q_{t}}=\frac{t}{q_{e}}+\frac{1}{k_{2} q_{e}^{2}}
\end{gathered}
$$

where $q_{t}$ is the adsorption capacity at time $t(\mathrm{~h})$, and the $k_{1}\left(\mathrm{~min}^{-1}\right)$ and $k_{2}\left(\mathrm{~g} \mathrm{mg}^{-1} \mathrm{~min}^{-1}\right)$ are adsorption rate constant of the pseudo-first-order and pseudo-second-order kinetics models, respectively.

\subsection{Adsorption Isotherm Model}

The Langmuir isotherm adsorption model assumed that adsorption occurred uniformly at all active sites of the adsorbent and that the dye was adsorbed as a monolayer on its surface [50]. The Freundlich isotherm adsorption model assumed that the surface energy of the adsorbent was not uniform and that the dye was not adsorbed in a single monolayer on the adsorbent surface [51]. The Tempkin adsorption isotherm model assumed a linear decreased heat of adsorption of the dye by the adsorbent [52]. These isotherm adsorption models equations are shown as follows [53-55].

$$
\begin{gathered}
\text { Langmuir : } \frac{C_{e}}{q_{e}}=\frac{C_{e}}{q_{m}}+\frac{1}{q_{m} k_{L}} \\
\text { Freundlich : } \ln q_{e}=\frac{1}{n} \ln C_{e}+\ln k_{F} \\
\text { Tempkin : } q_{e}=B \ln C_{e}+B \ln A
\end{gathered}
$$

where $q_{m}\left(\mathrm{mg} \mathrm{g}^{-1}\right)$ and $k_{L}\left(\mathrm{~L} \mathrm{mg}^{-1}\right)$ represent the maximum adsorption capacity of adsorbents and Langmuir constant, separately; the $k_{F}\left[\left(\mathrm{mg} \mathrm{g}^{-1}\right)\left(\mathrm{L} \mathrm{mg}^{-1}\right)^{1 / n}\right]$ and $n$ are Freundlich constants representing adsorption capacity and adsorption intensity, separately; $B=(R T / b)$ is related to the heat of adsorption, and $A\left(\mathrm{~L} \mathrm{~g}^{-1}\right)$ is the equilibrium constant.

\subsection{Cyclic Adsorption Experiment}

After the model dye was adsorbed, $20 \mathrm{mg}$ of adsorbent was washed ultrasonically with $20 \mathrm{~mL}$ of ethanol for $30 \mathrm{~min}$ and centrifuged 5 times, then dried at $120{ }^{\circ} \mathrm{C}$ (under vacuum) for $2 \mathrm{~h}$. The purified adsorbent was then used for the next adsorption process.

\section{Results and Discussion}

\subsection{Characterization of Samples}

The TEM and SEM images of the sample are shown in Figure 1. The morphologies of 220-MIL-101, 200-MIL-101, and 180-MIL-101 were regularly octahedral crystals. According 
to the particle size distribution (Figure S2), it could be seen that 220-MIL-101 possessed the largest particle size about $382 \mathrm{~nm}$, while the particles of 200-MIL-101 (153 nm) and 180-MIL-101 (215 nm) were much smaller. Therefore, 160-MIL-101 revealed a spherical morphology with an average particle size of about $265 \mathrm{~nm}$. Because the crystal formation process was controlled by kinetic factors, that shape is the final morphological structure. Under low-temperature reaction conditions $\left(160^{\circ} \mathrm{C}\right)$, the surface energy of crystal growth was insufficient, the morphology would not be able to form an angled regular octahedron and cause spherical crystals.

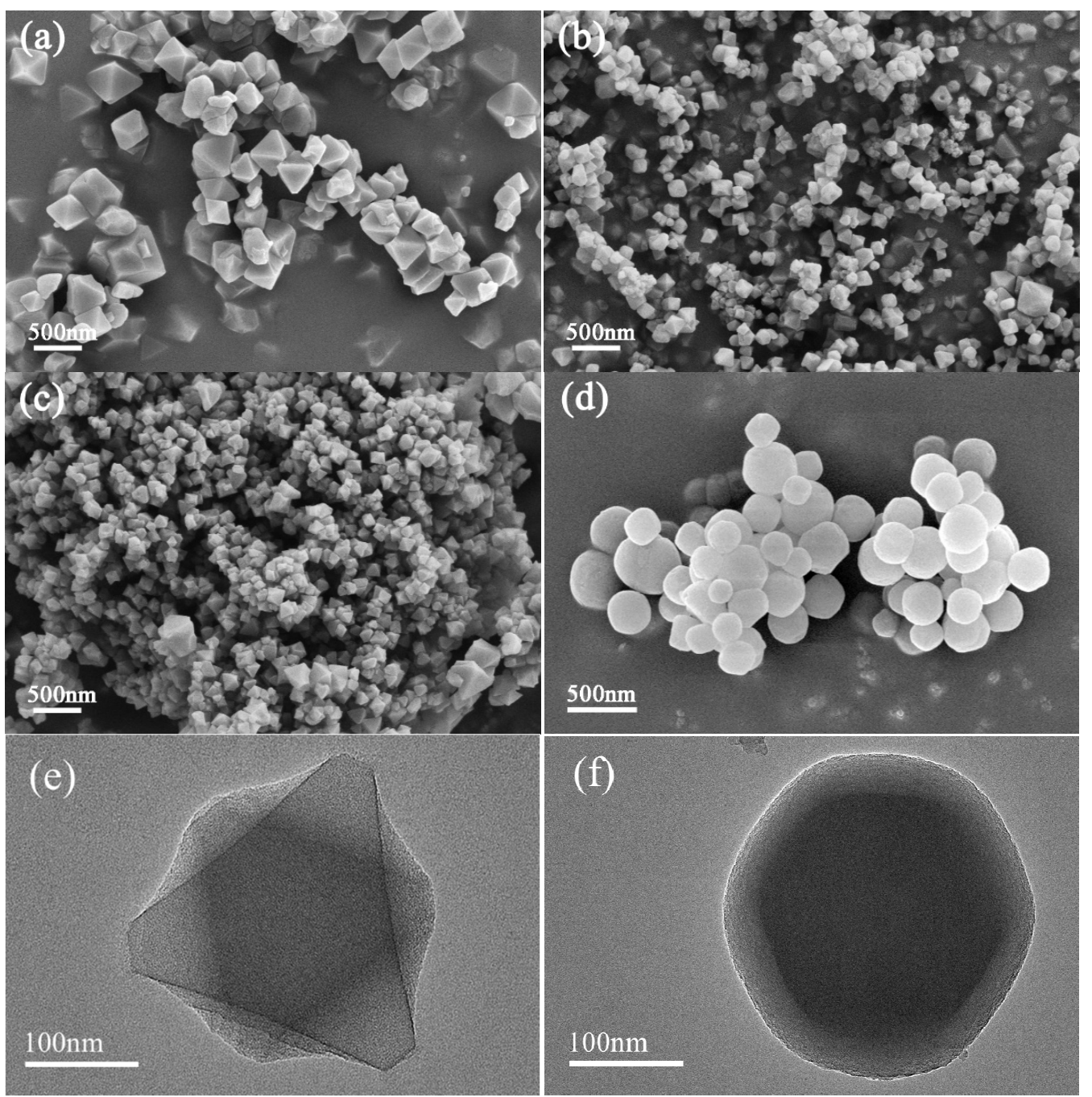

Figure 1. SEM images of (a) 220-MIL-101, (b) 200-MIL-101, (c) 180-MIL-101, and (d) 160-MIL-101. HRTEM images of (e) 200-MIL-101 and (f) 160-MIL-101.

The XRD patterns of 220-MIL-101, 200-MIL-101, 180-MIL-101, and 160-MIL-101 were consistent with the simulated MIL-101 pattern, which confirmed that all samples were MIL-101(Cr) (Figure 2). The low-angle region of the PXRD patterns also gave an additional confirmation that all the MIL-101(Cr) compounds are practically pure (Figure S3).

The $\mathrm{N}_{2}$ adsorption-desorption isotherms of 220-MIL-101, 200-MIL-101, 180-MIL-101, and 160-MIL-101 were presented in Figure 2. 160-MIL-101 showed the highest BET surface area of $3021 \mathrm{~m}^{2} \mathrm{~g}^{-1}$, 200-MIL-101 and 180-MIL-101 showed slightly smaller BET surface areas of 2926 and $2909 \mathrm{~m}^{2} \mathrm{~g}^{-1}$, respectively. While 220-MIL-101, which followed the initial literature [19], displayed the lowest BET surface area of $2862 \mathrm{~m}^{2} \mathrm{~g}^{-1}$ (Table 1). Interestingly, the yields of all samples were over $50 \%$, which was higher than the reported HF route ( 50\%) [32-34]. Most notably, with 200-MIL-101, the yield was above 95\%, which might be 
the highest value ever reported. Hence, the additive-free route for MIL-101(Cr) at lower temperatures could be considered as an alternative for industrial production.

(a)

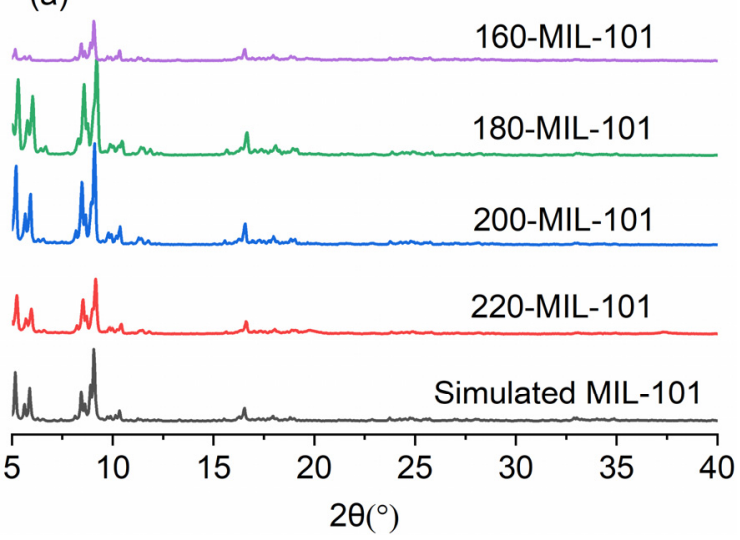

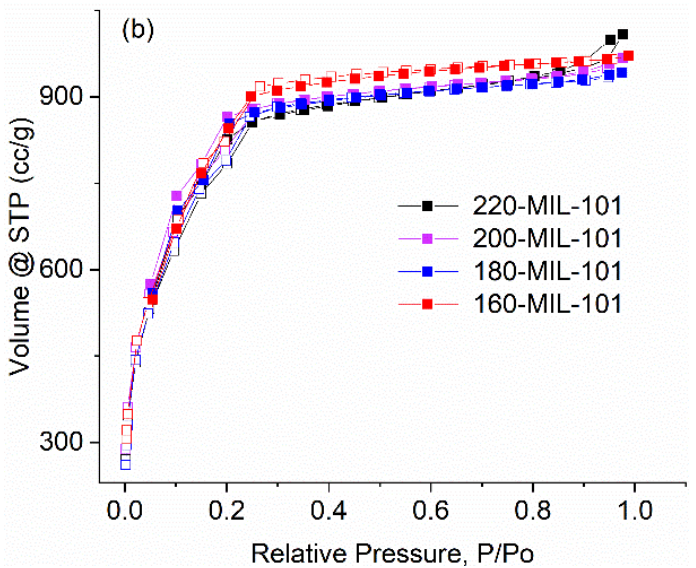

Figure 2. (a) XRD patterns of the samples, (b) the $\mathrm{N}_{2}$ adsorption-desorption isotherms of the samples.

Table 1. Yield, particle size, surface area, and pore volume of samples.

\begin{tabular}{|c|c|c|c|c|c|}
\hline Sample & $\underset{\%}{\text { Yield/ }}$ & $\begin{array}{c}\text { Particle Size/ } \\
n^{\text {m }}\end{array}$ & $\begin{array}{c}S_{\mathrm{BET}} / \\
\left(\mathrm{m}^{2} \mathrm{~g}^{-1}\right)^{\mathrm{c}}\end{array}$ & $\begin{array}{c}S_{\text {Langmuir }} / \\
\left(\mathrm{m}^{2} \mathrm{~g}^{-1}\right)\end{array}$ & $\begin{array}{c}V_{\text {pore }} / \\
\left(\mathrm{cm}^{3} \mathrm{~g}^{-1}\right)^{\mathrm{d}}\end{array}$ \\
\hline 220-MIL-101 & 76.6 & $382(8)$ & 2862 & 4038 & 1.6 \\
\hline 200-MIL-101 & 95.6 & $153(3)$ & 2926 & 4651 & 1.5 \\
\hline 180-MIL-101 & 77.8 & $215(3)$ & 2909 & 4080 & 1.5 \\
\hline 160-MIL-101 & 52.7 & $265(3)$ & 3021 & 4183 & 1.5 \\
\hline
\end{tabular}

a The yield is based on Cr:BDC ratio is always 1:1. ${ }^{\mathrm{b}}$ The average particle size obtained by Gaussian model statistics, the value in parentheses is the standard deviation. ${ }^{c}$ Calculated in the pressure range $0.05<p / p_{0}<0.2$ from $\mathrm{N}_{2}$ sorption isotherms at $77 \mathrm{~K}$ with an estimated standard deviation of $\pm 50 \mathrm{~m}^{2} \mathrm{~g}^{-1}$. d Calculated from $\mathrm{N}_{2}$ sorption isotherms at $77 \mathrm{~K}\left(p / p_{0}=0.95\right)$ for pores $\leq 20 \mathrm{~nm}$.

\subsection{Adsorption Capacity of Spherical MIL-101(Cr) for Dyes}

Currently, dyes are widely used in daily life-in applications such as food industry, packaging, and printing - and nearly $10-15 \%$ of the consumed dyes are directly discharged into the aqueous environment $[56,57]$. The dumped dyes not only compromise water quality, but they also do great harm to human health $[58,59]$. Thus, it is important to develop valid technologies for the removal of dyes from wastewater before being discharged into the environment. The adsorption method is considered one of the most promising removal strategies, due to its high efficiency, lower secondary pollution, and low cost $[59,60]$. MIL-101(Cr), a kind of high water/chemical MOF with high porosity and large pore volume, meets the demands of dye adsorption applications as an adsorbent. For instance, MIL-101(Cr) showed high adsorption efficiency toward MO in an aqueous solution [61]. Yang et al. reported that MIL-101(Cr) can be used as an adsorbent for the removal of Congo red (CR) [62]. Chen et al. found that MIL-101(Cr) exhibited high uptake toward xylenol orange $(\mathrm{XO})[63]$.

Herein, we select methyl orange (MO) and rhodamine $B(R B)$ as the model compounds for the adsorption experiments of MIL-101(Cr)s. Obviously, spherical MIL-101(Cr) (160MIL-101) exhibited the best adsorption capabilities toward MO and RB among all samples, with maximum uptakes of $444.3 \mathrm{mg} \mathrm{g}^{-1}$ and $230.3 \mathrm{mg} \mathrm{g}^{-1}$, respectively (Figure S4). Especially for the adsorption of MO, the uptake of 160-MIL-101 is significantly higher than that of other adsorbents which have been reported in recent years (Table 2) [64-72]. The uptake of 160-MIL-101 is also significantly higher than other MIL-101 and MIL-101 composites from several studies (Table S3) [23,61,73-78]. 
Table 2. Adsorption capacities (qmax) of MO on several adsorbents.

\begin{tabular}{|c|c|c|}
\hline Adsorbents & $q \max \left(\mathrm{mg} \mathrm{g}^{-1}\right)$ & Ref. \\
\hline Hyper-cross-linked aromatic Triazine porous polymer & 249.3 & [64] \\
\hline UiO-66- $\mathrm{NH}_{2}$ & 184.4 & {$[65]$} \\
\hline CoFe-nitrate-layered double Hydroxides & 27.6 & [66] \\
\hline Nitrogen-doped nanoporous carbon & 222.2 & {$[67]$} \\
\hline Cd-based MOF & 167 & [68] \\
\hline ZIF-67 composite & 180 & [69] \\
\hline $\mathrm{Fe}_{3} \mathrm{O}_{4} @ \mathrm{SiO}_{2} @ \mathrm{UiO}-66$ & 219 & [70] \\
\hline Zwitterionic MOFs@CNF & 49.2 & [71] \\
\hline PANI@ Activated Carbon & 192.5 & [72] \\
\hline 160-MIL-101 & 444.3 & This work \\
\hline
\end{tabular}

Figure 3 revealed the maximum adsorption capabilities of 160-MIL-101 toward MO and RB. Absolutely, 160-MIL-101 presented a higher adsorption capability of MO than that of RB. This result implied that the adsorption performance was dye-specific and also closely associated with the MIL-101(Cr) characteristics and the molecular dye structures. The structures of MO and RB were shown in Figure S5, MO was anionic dye, whereas $\mathrm{MB}$ was cationic. The RB molecule possessed more aromatic rings than $\mathrm{MO}$, while $\mathrm{MO}$ had a smaller molecular size in comparison with RB. The zeta potential of the spherical MIL-101(Cr) crystallite was $19.1 \mathrm{mv}$ (Figure S6), which indicated that the surfaces of 160MIL-101 were positively charged. Thus, the difference could significantly affect the $\pi-\pi$ interactions, electrostatic interactions, and steric hindrance between the MIL-101(Cr)s and the dyes (Figure 4).

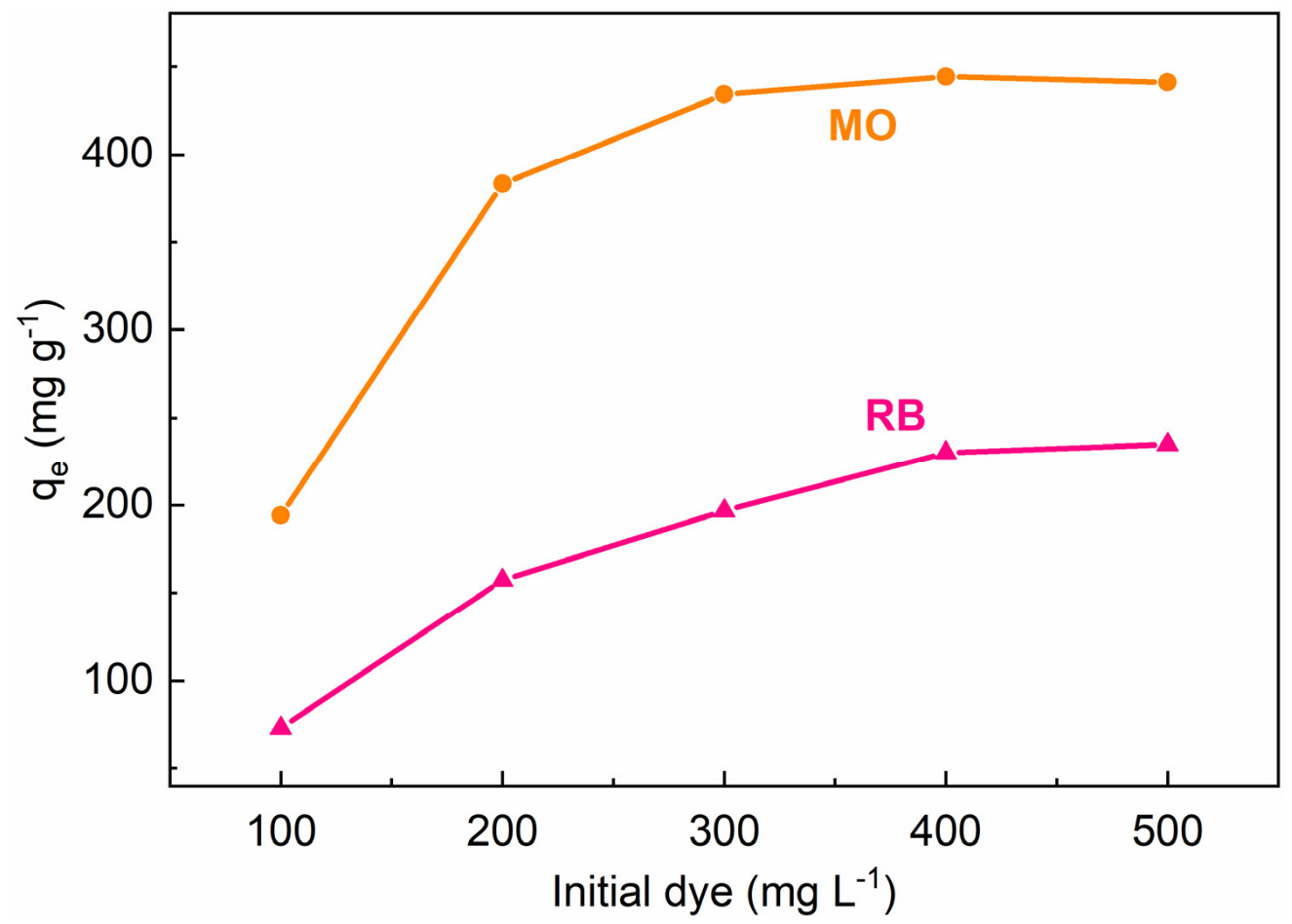

Figure 3. Adsorption uptakes of 160-MIL-101 toward MO and RB after $24 \mathrm{~h}$, as determined by dispersing $5 \mathrm{mg}$ of 160 -MIL-101 in the aqueous dye solution $\left(100 \mathrm{mg} \mathrm{L}^{-1}\right.$ to $\left.500 \mathrm{mg} \mathrm{L}^{-1}\right)$ at ambient temperature $\left(25^{\circ} \mathrm{C}\right)$. 


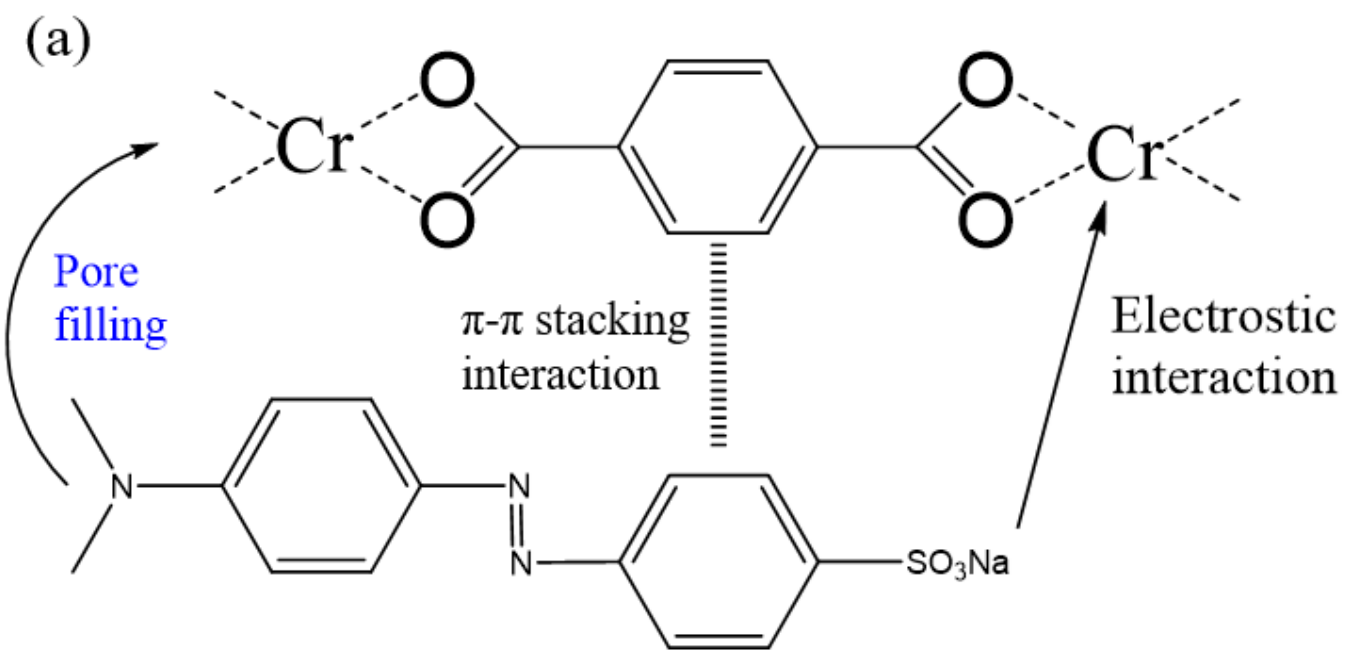

(b)

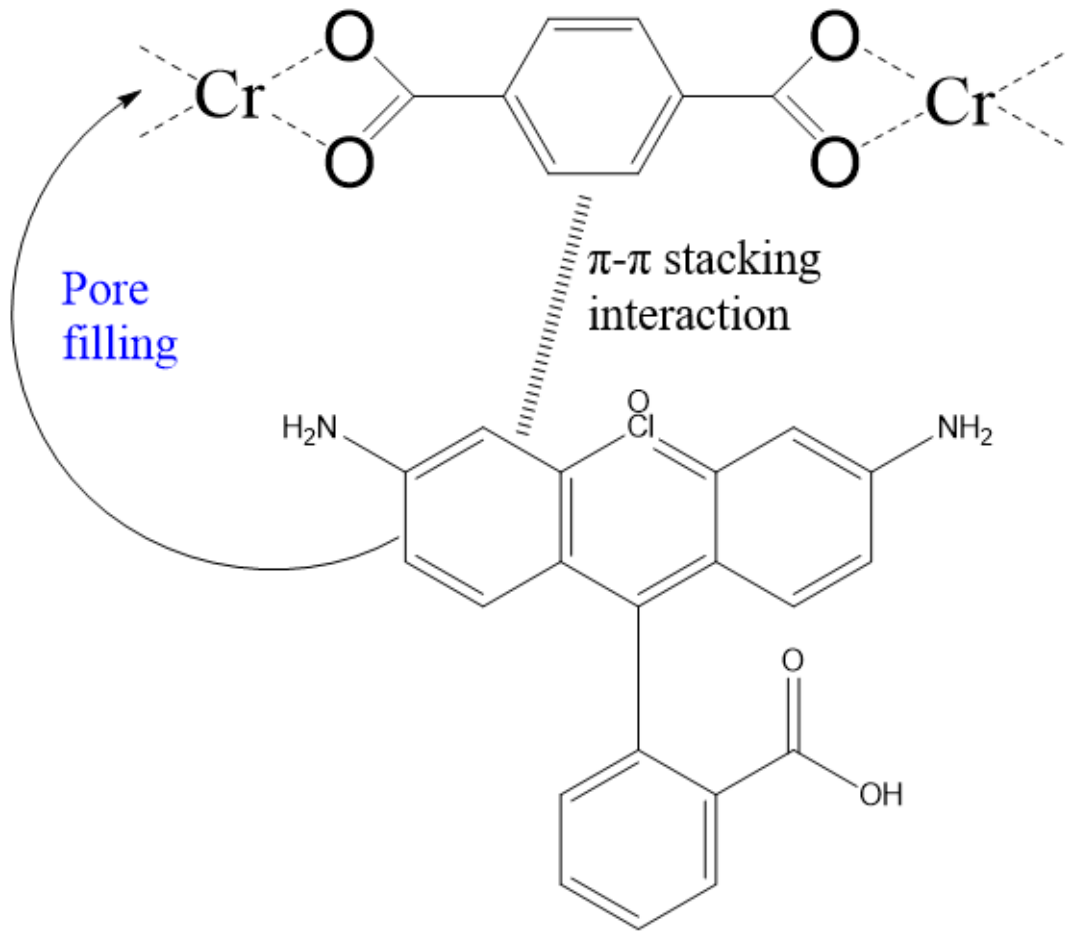

Figure 4. Possible mechanism of synergetic interplay for (a) MO and (b) RB adsorption on 160-MIL-101.

The possible mechanism of improvement of MO adsorption by spherical MIL-101(Cr) may be attributed to its higher surface area and the positive charge may be more evenly distributed on the surface. The former could significantly increase the adsorption capability of $\mathrm{MO}$, while the latter is also conducive to promoting adsorption of anionic MO. Thus, in our case, the spherical MIL-101(Cr) (160-MIL-101) presented higher adsorption capability of $\mathrm{MO}$ than other octahedral MIL-101(Cr).

The time-dependent adsorption capacity of 160-MIL-101 for dyes was investigated, as shown in Figure S7. The adsorption kinetics curves which were fitted with Equations (2) and (3) were displayed in Figure 5, and the corresponding parameters are listed in Table S4. Obviously, the correlation coefficients (i.e., $\mathrm{R}^{2}$ values) of the pseudo-second-order kinetics model were higher than those of the pseudo-first-order model, and the theoretical equilibrium adsorption capacity, theoretical $q_{e}$, was highly consistent with the experimental data (Table S4). Thus, it is indicated that the adsorption of MO and RB by $160-\mathrm{MIL}-101(\mathrm{Cr})$ was mainly a pseudo-secondorder procedure. 

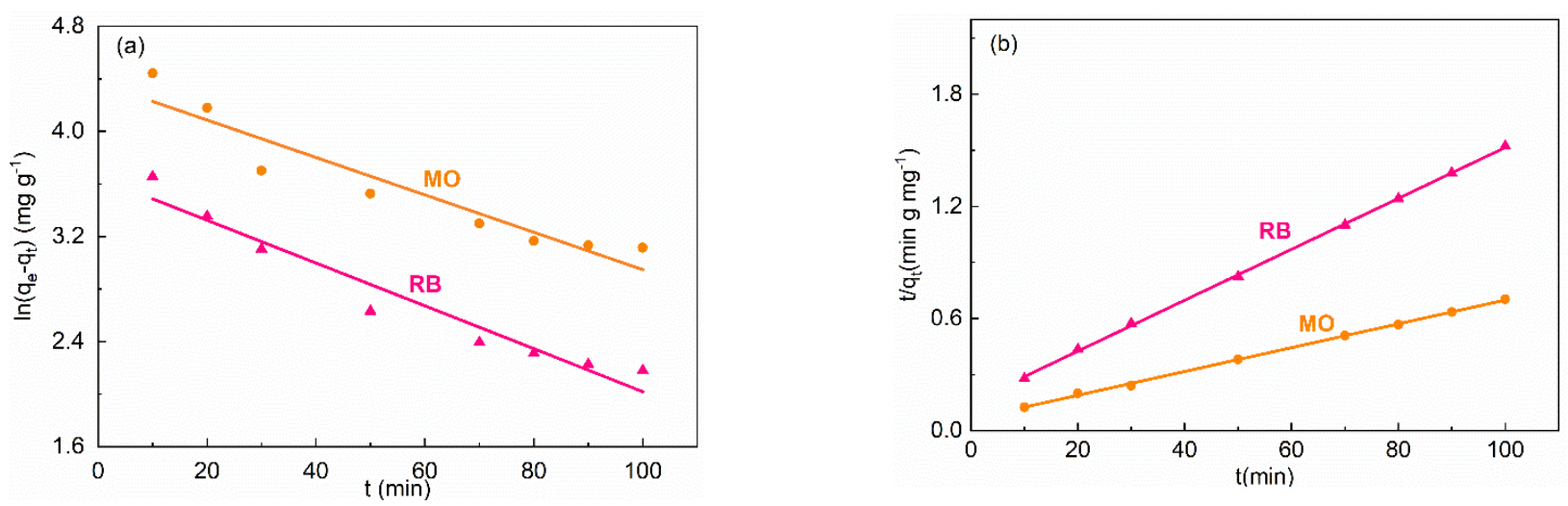

Figure 5. (a) Pseudo-first-order and (b) pseudo-second-order of the kinetics data.

The Langmuir, Freundlich, and Tempkin isotherm models were employed to fit the experimental data (the models were described in Experimental 2.6). Figure 6 revealed the equilibrium adsorption isotherms for $\mathrm{MO}$ and $\mathrm{RB}$, and the related fitting parameters were listed in Table S4. For the adsorption of MO and RB by 160-MIL-101, the experimental adsorption data were in good agreement with the Langmuir isotherm model, especially in the case of MO, the correlation regression coefficient of $R^{2}$ was over 0.99 , which was higher than that of Temkin and Freundlich models (Figure 6, Table S4). Moreover, according to the Langmuir model, the theoretical maximum adsorption capability of 160-MIL-101 toward MO was in line with the experimental data (Table S4).
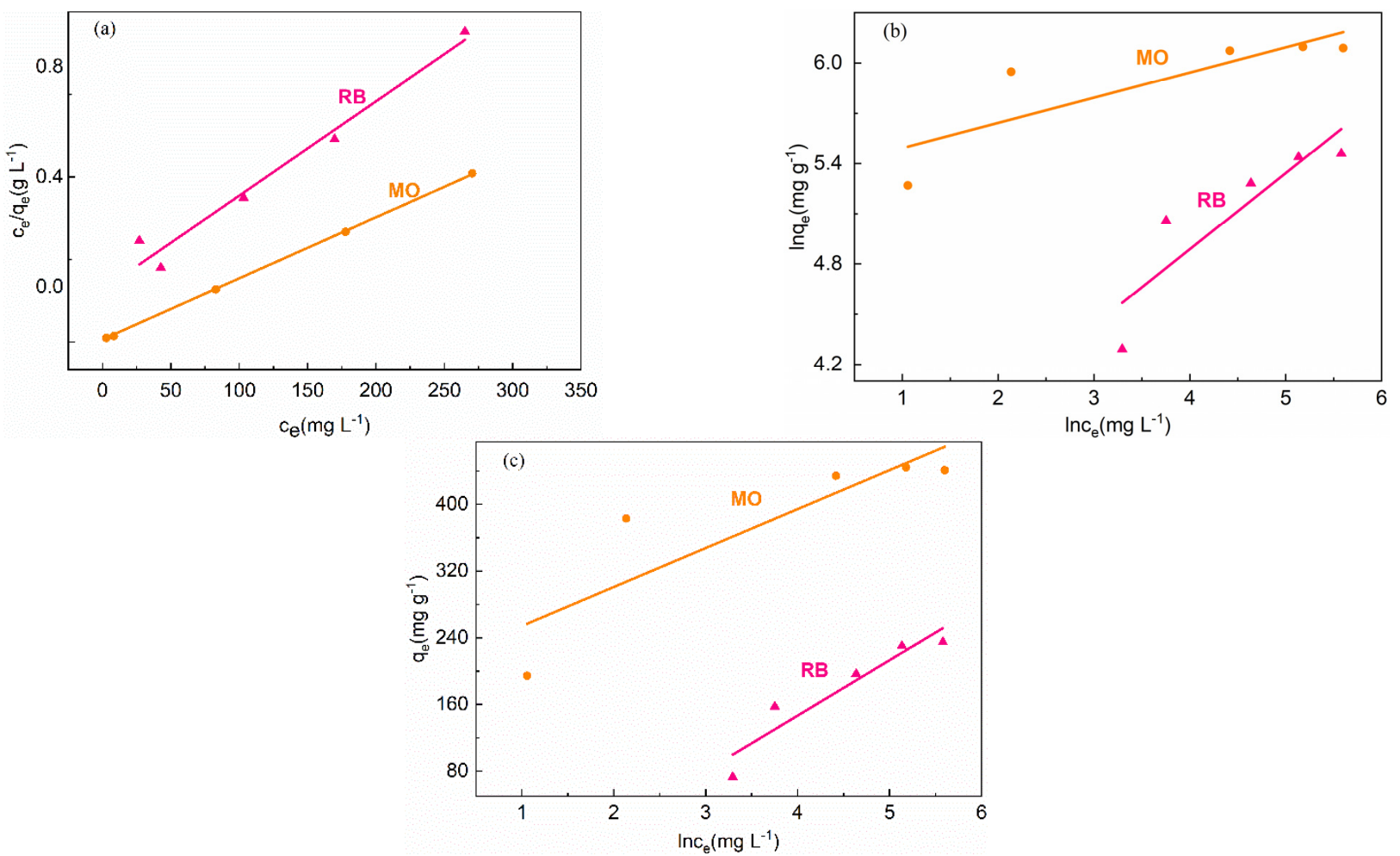

Figure 6. Experimental data for the adsorption of dyes on160-MIL-101 analyzed using (a) Langmuir, (b) Freundlich, and (c) Temkin models.

The regeneration and reusability of the MIL-101(Cr) adsorbent will be important for the industrial applications. Thus, the regeneration of 160-MIL-101 adsorbent was investigated by using ethanol as an extracting regenerating agent. After five successive adsorption-desorption cycles, the adsorption uptake of 160-MIL-101 toward MO decreased 
by $<10 \%$, indicating that MIL-101(Cr) exhibited excellent reusability toward dye adsorption (Figure S8).

\section{Conclusions}

In conclusion, we have demonstrated an additive-free strategy for control of the morphology of MIL-101(Cr) by hydrothermal synthesis at relatively lower temperatures. Spherical MIL-101(Cr) could be obtained at a relatively lower temperature at $160{ }^{\circ} \mathrm{C}$. It showed good adsorption capacity toward MO $\left(444.3 \mathrm{mg} \mathrm{g}^{-1}\right)$ and RB $\left(230.3 \mathrm{mg} \mathrm{g}^{-1}\right)$. The analyzed results suggested that a plausible adsorption mechanism was attributed to the synergetic interplay based on porosity, $\pi-\pi$ interactions, electrostatic interactions, and steric hindrance influence. Hence, an alternative strategy for the industrial fabrication of MIL-101(Cr) is proposed, with potential for the extension of the application of MIL-101(Cr) in effluent treatment fields, mixed matrix membranes, and other contexts.

Supplementary Materials: The following supporting information can be downloaded at: https: / / www.mdpi.com/article/10.3390/inorganics10030033/s1, Figure S1: Building blocks for MIL101(Cr); Figure S2: Particle size distribution of samples; Figure S3: The low-angle region of the PXRD patterns of all MIL-101(Cr)s; Figure S4: The adsorption capabilities of all MIL-101(Cr)s toward MO and RB; Figure S5: Dye molecule diagram, (a) MO and (b) RB; Figure S6: Zeta potential of 160-MIL-101 directly dispersed in water; Figure S7: Impact of the time on the adsorption of (a) MO and (b) RB onto 160-MIL-101; Figure S8: Recycle of the removal efficiency of 160-MIL-101 for MO; Table S1: Price parameters of MIL-101(Cr) sold by various manufacturers; Table S2: BET specific surface area, pore volume and yield of MIL-101(Cr) synthesized by various additives; Table S3: Adsorption capacities (qmax) of MO on other MIL-101 and MIL-101 composite; Table S4: Characteristic parameters of the adsorption of dyes on the 160-MIL-101.

Author Contributions: Conceptualization, T.Z.; Methodology, T.Z. and X.L.; Formal Analysis, M.Z., S.T. and M.L.; Investigation, H.Z., M.D. and M.Z.; Resources, T.Z. and X.L.; Writing-Original Draft Preparation, H.Z. and M.D.; Writing-Review \& Editing, Supervision and Funding Acquisition, T.Z. All authors have read and agreed to the published version of the manuscript.

Funding: The National Natural Science Foundation of China (51802094, 51927810); the Science and Technology Program of Hunan Province, China (2018RS3084) and the Research Foundation of Education Department of Hunan Province, China (18B288).

Acknowledgments: The work was supported by the National Natural Science Foundation of China (51802094, 51927810); the Science and Technology Program of Hunan Province, China (2018RS3084); the Research Foundation of Education Department of Hunan Province, China (18B288).

Conflicts of Interest: The authors declare no conflict of interest.

\section{References}

1. Yaghi, O.M.; O'Keeffe, M.; Ockwig, N.W.; Chae, H.K.; Eddaoudi, M.; Kim, J. Reticular synthesis and the design of new materials. Nature 2003, 423, 705-714. [CrossRef]

2. Rosi, N.L.; Eckert, J.; Eddaoudi, M.; Vodak, D.T.; Kim, J.; O’Keeffe, M.; Yaghi, O.M. Hydrogen storage in microporous metalorganic frameworks. Science 2003, 300, 1127-1129. [CrossRef] [PubMed]

3. Farha, O.K.; Eryazici, I.; Jeong, N.C.; Hauser, B.G.; Wilmer, C.E.; Sarjeant, A.A.; Snurr, R.Q.; Nguyen, S.T.; Yazaydın, A.Ö.; Hupp, J.T. Metal-organic framework materials with ultrahigh surface areas: Is the sky the limit? J. Am. Chem. Soc. 2012, 134, 15016-15021. [CrossRef]

4. $\quad$ Furukawa, H.; Ko, N.; Go, Y.B.; Aratani, N.; Choi, S.B.; Choi, E.; Yazaydin, A.Ö.; Snurr, R.Q.; O’Keeffe, M.; Kim, J.; et al. Ultrahigh porosity in metal-organic frameworks. Science 2010, 329, 424-428. [CrossRef]

5. $\mathrm{Li}, \mathrm{C}$.; $\mathrm{Li}, \mathrm{H} . ; \mathrm{Ai}, \mathrm{J} . ;$ Chen, J.; Du, M. Optimizing strategy for enhancing the stability and ${ }^{99} \mathrm{TcO}_{4}{ }^{-}$sequestration of poly(ionic liquids)@MOFs composites. ACS Cent. Sci. 2020, 6, 2354-2361. [CrossRef]

6. Fan, W.; Wang, X.; Xu, B.; Wang, Y.; Liu, D.; Zhang, M.; Shang, Y.; Dai, F.; Zhang, L.; Sun, D. Amino-functionalized MOFs with high physicochemical stability for efficient gas storage/separation, dye adsorption and catalytic performance. J. Mater. Chem. A 2018, 6, 24486-24495. [CrossRef]

7. Jayaramulu, K.; Geyer, F.; Schneemann, A.; Kment, Š.; Otyepka, M.; Zboril, R.; Vollmer, D.; Fischer, R.A. Hydrophobic metalorganic frameworks. Adv. Mater. 2019, 31, 1900820-1900850. [CrossRef] [PubMed] 
8. Zhang, X.; Chen, A.; Zhong, M.; Zhang, Z.; Zhang, X.; Zhou, Z.; Bu, X.-H. Metal-organic frameworks (MOFs) and MOF-derived materials for energy storage and conversion. Electrochem. Energy Rev. 2018, 2, 29-104. [CrossRef]

9. Nie, X.; Kulkarni, A.; Sholl, D.S. Computational prediction of metal organic frameworks suitable for molecular infiltration as a route to development of conductive materials. J. Phys. Chem. Lett. 2015, 6, 1586-1591. [CrossRef]

10. Lin, C.; He, H.; Zhang, Y.; Xu, M.; Tian, F.; Li, L.; Wang, Y. Acetaldehyde-modified-cystine functionalized Zr-MOFs for pH/GSH dual-responsive drug delivery and selective visualization of GSH in living cells. RSC Adv. 2020, 10, 3084-3091. [CrossRef]

11. Zhang, L.; Liu, H.; Shi, W.; Cheng, P. Synthesis strategies and potential applications of metal-organic frameworks for electrode materials for rechargeable lithium ion batteries. Coord. Chem. Rev. 2019, 388, 293-309. [CrossRef]

12. Rivera-Torrente, M.; Mandemaker, L.D.B.; Filez, M.; Delen, G.; Seoane, B.; Meirer, F.; Weckhuysen, B.M. Spectroscopy, microscopy, diffraction and scattering of archetypal MOFs: Formation, metal sites in catalysis and thin films. Chem Soc. Rev. 2020, 49, 6694-6732. [CrossRef] [PubMed]

13. Alzamly, A.; Bakiro, M.; Hussein Ahmed, S.; Alnaqbi, M.A.; Nguyen, H.L. Rare-earth metal-organic frameworks as advanced catalytic platforms for organic synthesis. Coord. Chem. Rev. 2020, 425, 213543-213565. [CrossRef]

14. Zhang, W.; Wang, X.; Li, P.; Zhang, W.; Wang, H.; Tang, B. Evaluating hyperthyroidism-induced liver injury based on in situ fluorescence imaging of glutathione and phosphate via Nano-MOFs sensor. Anal. Chem. 2020, 92, 8952-8958. [CrossRef]

15. Ren, K.; Guo, X.; Tang, Y.; Huang, B.; Wang, H. Size-controlled synthesis of metal-organic frameworks and their performance as fluorescence sensors. Analyst 2020, 145, 7349-7356. [CrossRef]

16. Wu, Z.; Gu, A.; Gao, N.; Cui, H.; Wang, W.; Cui, J. Solvent-dependent assembly and magnetic relaxation behaviors of $\left[\mathrm{Cu}_{4} \mathrm{I}_{3}\right]$ cluster-based lanthanide MOFs: Acting as efficient catalysts for carbon dioxide conversion with propargylic alcohols. Inorg. Chem. 2020, 59, 15111-15119. [CrossRef]

17. Wang, Y.; Zhang, H.; Wang, D.; Sheng, N.; Zhang, G.; Yin, L.; Sha, J. Development of a uricase-free colorimetric biosensor for uric acid based on PPy-coated polyoxometalate-encapsulated fourfold helical metal-organic frameworks. ACS Biomater. Sci. Eng. 2020, 6, 1438-1448. [CrossRef]

18. Yang, F.; Yang, G.; Wu, Y.; Yan, Y.; Liu, J.; Gao, R.; Zhang, W.; Wang, Y. Ln(III)-MOFs (Ln=Tb, Eu, Dy, and Sm) based on triazole carboxylic ligand with carboxylate and nitrogen donors with applications as chemical sensors and magnetic materials. J. Coord. Chem. 2018, 71, 2702-2713. [CrossRef]

19. Férey, G.; Mellot-Draznieks, C.; Serre, C.; Millange, F. A Chromium Terephthalate-Based Solid with Unusually Large Pore Volumes and Surface Area. Science 2005, 309, 2040-2042. [CrossRef]

20. Hong, D.; Hwang, Y.K.; Serre, C.; Férey, G.; Chang, J. Porous Chromium Terephthalate MIL-101 with Coordinatively Unsaturated Sites: Surface Functionalization, Encapsulation, Sorption and Catalysis. Adv. Funct. Mater. 2009, 19, 1537-1552. [CrossRef]

21. Niknam, E.; Panahi, F.; Khalafi-Nezhad, A. Immobilized Pd on a NHC functionalized metal-organic framework MIL-101(Cr): An efficient heterogeneous catalyst in Suzuki-Miyaura coupling reaction in water. Appl. Organomet. Chem. 2020, 34, 5470. [CrossRef]

22. Oudi, S.; Oveisi, A.R.; Daliran, S.; Khajeh, M.; Teymoori, E. Brønsted-Lewis dual acid sites in a chromium-based metal-organic framework for cooperative catalysis: Highly efficient synthesis of quinazolin-(4H)-1-one derivatives. J. Colloid Interface Sci. 2020, 561, 782-792. [CrossRef] [PubMed]

23. Wu, W.; Yao, T.; Xiang, Y.; Zou, H.; Zhou, Y. Efficient removal of methyl orange by a flower-like TiO2/MIL-101(Cr) composite nanomaterial. Dalton Trans. 2020, 49, 5722-5729. [CrossRef]

24. Liu, Z.; Gao, J.; Qi, X.; Zhao, Z.; Sun, H. Experimental study on activated carbon-MIL-101(Cr) composites for ethanol vapor adsorption. Materials 2021, 14, 3811. [CrossRef]

25. Song, N.; Sun, Y.; Xie, X.; Wang, D.; Shao, F.; Yu, L.; Dong, L. Doping MIL-101(Cr)@GO in polyamide nanocomposite membranes with improved water flux. Desalination 2020, 492, 114601-114607. [CrossRef]

26. Kavun, V.; van der Veen, M.A.; Repo, E. Selective recovery and separation of rare earth elements by organophosphorus modified MIL-101(Cr). Microporous Mesoporous Mater. 2021, 312, 110747. [CrossRef]

27. Latifi, L.; Sohrabnezhad, S. Drug delivery by micro and meso metal-organic frameworks. Polyhedron 2020, 180, 114321. [CrossRef]

28. Markopoulou, P.; Panagiotou, N.; Li, A.; Bueno-Perez, R.; Madden, D.; Buchanan, S.; Fairen-Jimenez, D.; Shiels, P.G.; Forgan, R.S. Identifying differing intracellular cargo release mechanisms by monitoring in vitro drug delivery from MOFs in real time. Cell Rep. Phys. Sci. 2020, 1, 100254. [CrossRef]

29. Hong, W.Y.; Perera, S.P.; Burrows, A.D. Comparison of MIL-101(Cr) metal-organic framework and $13 \mathrm{X}$ zeolite monoliths for $\mathrm{CO}_{2}$ capture. Microporous Mesoporous Mater. 2020, 308, 110525. [CrossRef]

30. Sáenz Cavazos, P.A.; Díaz-Ramírez, M.L.; Hunter-Sellars, E.; McIntyre, S.R.; Lima, E.; Ibarra, I.A.; Williams, D.R. Fluorinated MIL-101 for carbon capture utilisation and storage: Uptake and diffusion studies under relevant industrial conditions. RSC Adv. 2021, 11, 13304-13310. [CrossRef]

31. Sun, Y.; Liang, J.; Brandt, P.; Spieß, A.; Öztürk, S.; Janiak, C. Cucurbit[6]uril@MIL-101-Cl: Loading polar porous cages in mesoporous stable host for enhanced $\mathrm{SO}_{2}$ adsorption at low pressures. Nanoscale 2021, 13, 15952-15962. [CrossRef]

32. Ferreira, I.C.; Ferreira, T.J.; Barbosa, A.D.S.; de Castro, B.; Ribeiro, R.P.P.L.; Mota, J.P.B.; Alves, V.D.; Cunha-Silva, L.; Esteves, I.A.A.C.; Neves, L.A. Cr-based MOF/IL composites as fillers in mixed matrix membranes for CO2 separation. Sep. Purif. Technol. 2021, 276, 119303. [CrossRef]

33. Guo, Z.; Liu, Z.; Zhang, K.; Wang, W.; Pang, J.; Li, Z.; Kang, Z.; Zhao, D. Stable metal-organic frameworks based mixed matrix membranes for Ethylbenzene/ $\mathrm{N}_{2}$ separation. Chem. Eng. J. 2021, 416, 129193. [CrossRef] 
34. Sheikh Alivand, M.; Hossein Tehrani, N.H.M.; Shafiei-alavijeh, M.; Rashidi, A.; Kooti, M.; Pourreza, A.; Fakhraie, S. Synthesis of a modified HF-free MIL-101(Cr) nanoadsorbent with enhanced $\mathrm{H}_{2} \mathrm{~S} / \mathrm{CH}_{4}, \mathrm{CO}_{2} / \mathrm{CH}_{4}$, and $\mathrm{CO}_{2} / \mathrm{N}_{2}$ selectivity. J. Environ. Chem. Eng. 2019, 7, 102946. [CrossRef]

35. Rallapalli, P.B.S.; Raj, M.C.; Senthilkumar, S.; Somani, R.S.; Bajaj, H.C. HF-free synthesis of MIL-101(Cr) and its hydrogen adsorption studies. Environ. Prog. Sustain. Energy 2016, 35, 461-468. [CrossRef]

36. Zhao, T.; Li, S.; Shen, L.; Wang, Y.; Yang, X.-Y. The sized controlled synthesis of MIL-101(Cr) with enhanced $\mathrm{CO}_{2}$ adsorption property. Inorg. Chem. Commun. 2018, 96, 47-51. [CrossRef]

37. Noorpoor, Z.; Pakdehi, S.G.; Rashidi, A. High capacity and energy-efficient dehydration of liquid fuel 2-dimethyl amino ethyl azide (DMAZ) over chromium terephthalic (MIL-101) nanoadsorbent. Adsorption 2017, 23, 743-752. [CrossRef]

38. Vohra, R.; Velez, L.I.; Rivera, W.; Benitez, F.L.; Delaney, K.A. Recurrent life-threatening ventricular dysrhythmias associated with acute hydrofluoric acid ingestion: Observations in one case and implications for mechanism of toxicity. Clin. Toxicol. 2008, 46, 79-84. [CrossRef]

39. Zhao, T.; Yang, L.; Feng, P.; Gruber, I.; Janiak, C.; Liu, Y. Facile synthesis of nano-sized MIL-101(Cr) with the addition of acetic acid. Inorg. Chim. Acta 2018, 471, 440-445. [CrossRef]

40. Lammert, M.; Bernt, S.; Vermoortele, F.; De Vos, D.E.; Stock, N. Single-and mixed-linker Cr-MIL-101 derivatives: A highthroughput investigation. Inorg. Chem. 2013, 52, 8521-8528. [CrossRef]

41. Mortazavi, S.S.; Abbasi, A.; Masteri Farahani, M.; Farzaneh, F. Sulfonic acid functionalized MIL-101(Cr) metal-organic framework for catalytic production of acetals. ChemistrySelect 2019, 4, 7495-7501. [CrossRef]

42. Khan, N.A.; Kang, I.J.; Seok, H.Y.; Jhung, S.H. Facile synthesis of nano-sized metal-organic frameworks, chromiumbenzenedicarboxylate, MIL-101. Chem. Eng. J. 2011, 166, 1152-1157. [CrossRef]

43. Yang, L.; Zhao, T.; Boldog, I.; Janiak, C.; Yang, X.Y.; Li, Q.; Zhou, Y.J.; Xia, Y.; Lai, D.W.; Liu, Y.J. Benzoic acid as a selector-modulator in the synthesis of MIL-88B(Cr) and Nano-MIL-101(Cr). Dalton Trans. 2019, 48, 989-996. [CrossRef] [PubMed]

44. Guo, J.; Chen, Y.; Jing, Y. Synthesis of metal organic framework MIL-101 with acetate as mineralization agent. Chem. J. Chin. Univeritie 2012, 33, 668-672.

45. Li, X.; Zhang, W.; Huang, Y.; Wang, Q.; Yang, J. Superior adsorptive removal of azo dyes from aqueous solution by a Ni(II)-doped metal-organic framework. Colloids Surf. A Physicochem. Eng. Asp. 2021, 619, 126549-126556. [CrossRef]

46. Li, W.; Liu, Y.Y.; Bai, Y.; Wang, J.; Pang, H. Anchoring ZIF-67 particles on amidoximerized polyacrylonitrile fibers for radionuclide sequestration in wastewater and seawater. J. Hazard. Mater. 2020, 395, 122692. [CrossRef]

47. Xu, J.; Cao, Z.; Zhang, Y.; Yuan, Z.; Lou, Z.; Xu, X.; Wang, X. A review of functionalized carbon nanotubes and graphene for heavy metal adsorption from water: Preparation, application, and mechanism. Chemosphere 2018, 195, 351-364. [CrossRef]

48. Huang, Y.-d. Comments on "Magnetically recoverable Ni@C composites: The synthesis by carbonization and adsorption for Fe3+". J. Alloys Compd. 2018, 739, 1124. [CrossRef]

49. Laciste, M.T.; de Luna, M.D.G.; Tolosa, N.C.; Lu, M.-C. Effect of calcination time of a quadruple-element doped titania nanoparticles in the photodegradation of gaseous formaldehyde under blue light irradiation. Chemosphere 2020, 246, 125763. [CrossRef]

50. Aigbe, U.O.; Onyancha, R.B.; Ukhurebor, K.E.; Obodo, K.O. Removal of fluoride ions using a polypyrrole magnetic nanocomposite influenced by a rotating magnetic field. RSC Adv. 2020, 10, 595-609. [CrossRef]

51. Chen, H.; Zhao, J. Adsorption study for removal of Congo red anionic dye using organo-attapulgite. Adsorption 2009, 15, 381-389. [CrossRef]

52. Sayın, M.; Can, M.; İmamoğlu, M. Adsorption of Pd(II) and Au(III) Ions by commercial tris(2-aminoethyl) amine polystyrene polymer beads. J. Chem. Eng. Data 2021, 66, 1132-1143. [CrossRef]

53. Tan, S.; Saito, K.; Hearn, M.T.W. Isothermal modelling of protein adsorption to thermo-responsive polymer grafted Sepharose Fast Flow sorbents. J. Sep. Sci. 2021, 44, 1884-1892. [CrossRef] [PubMed]

54. Ezzati, R. Derivation of Pseudo-First-Order, Pseudo-Second-Order and Modified Pseudo-First-Order rate equations from Langmuir and Freundlich isotherms for adsorption. Chem. Eng. J. 2020, 392, 123705. [CrossRef]

55. Pooladi, A.; Bazargan-Lari, R. Simultaneous removal of copper and zinc ions by Chitosan/Hydroxyapatite/nano-Magnetite composite. J. Mater. Res. Technol. 2020, 9, 14841-14852. [CrossRef]

56. Zhao, T.; Zhu, H.; Geng, W.; Zou, M.; Dong, M.; Ying, J. Morphology control synthesis of Cr-benzenedicarboxylate MOFs for the removal of methylene blue. J. Solid State Chem. 2022, 305, 122651. [CrossRef]

57. Rojas, S.; Horcajada, P. Metal-organic frameworks for the removal of emerging organic contaminants in water. Chem. Rev. 2020, 120, 8378-8415. [CrossRef]

58. Tan, K.B.; Vakili, M.; Horri, B.A.; Poh, P.E.; Abdullah, A.Z.; Salamatinia, B. Adsorption of dyes by nanomaterials: Recent developments and adsorption mechanisms. Sep. Purif. Technol. 2015, 150, 229-242. [CrossRef]

59. Liu, Q.; Yu, H.; Zeng, F.; Li, X.; Sun, J.; Li, C.; Lin, H.; Su, Z. HKUST-1 modified ultrastability cellulose/chitosan composite aerogel for highly efficient removal of methylene blue. Carbohydr. Polym. 2021, 255, 117402. [CrossRef]

60. Duan, C.; Meng, X.; Liu, C.; Lu, W.; Liu, J.; Dai, L.; Wang, W.; Zhao, W.; Xiong, C.; Ni, Y. Carbohydrates-rich corncobs supported metal-organic frameworks as versatile biosorbents for dye removal and microbial inactivation. Carbohydr. Polym. 2019, $222,115042$. [CrossRef] 
61. Haque, E.; Lee, J.E.; Jang, I.T.; Hwang, Y.K.; Chang, J.-S.; Jegal, J.; Jhung, S.H. Adsorptive removal of methyl orange from aqueous solution with metal-organic frameworks, porous chromium-benzenedicarboxylates. J. Hazard. Mater. 2010, 181, 535-542. [CrossRef] [PubMed]

62. Zhang, W.; Zhang, R.-Z.; Huang, Y.-Q.; Yang, J.-M. Effect of the synergetic interplay between the electrostatic interactions, size of the dye molecules, and adsorption sites of MIL-101(Cr) on the adsorption of organic dyes from aqueous solutions. Cryst. Growth Des. 2018, 18, 7533-7540. [CrossRef]

63. Chen, C.; Zhang, M.; Guan, Q.; Li, W. Kinetic and thermodynamic studies on the adsorption of xylenol orange onto MIL-101(Cr) Chem. Eng. J. 2012, 183, 60-67. [CrossRef]

64. Bekhoukh, A.; Moulefera, I.; Zeggai, F.Z.; Benyoucef, A.; Bachari, K. Anionic methyl orange removal from aqueous solutions by activated carbon reinforced conducting polyaniline as adsorbent: Synthesis, characterization, adsorption behavior, regeneration and kinetics study. J. Polym. Environ. 2021, 30, 886-895. [CrossRef]

65. Lv, S.; Liu, J.; Ma, H.; Wang, Z.; Li, C.; Zhao, N.; Wang, S. Simultaneous adsorption of methyl orange and methylene blue from aqueous solution using amino functionalized Zr-based MOFs. Microporous Mesoporous Mater. 2019, 282, 179-187. [CrossRef]

66. Ling, F.; Fang, L.; Lu, Y.; Gao, J.; Wu, F.; Zhou, M.; Hu, B. A novel CoFe layered double hydroxides adsorbent: High adsorption amount for methyl orange dye and fast removal of Cr(VI). Microporous Mesoporous Mater. 2016, 234, 230-238. [CrossRef]

67. Abo El Naga, A.O.; Shaban, S.A.; El Kady, F.Y.A. Metal organic framework-derived nitrogen-doped nanoporous carbon as an efficient adsorbent for methyl orange removal from aqueous solution. J. Taiwan Inst. Chem. Eng. 2018, 93, 363-373. [CrossRef]

68. Tella, A.C.; Olawale, M.D.; Neuburger, M.; Obaleye, J.A. Synthesis and crystal structure of Cd-based metal-organic framework for removal of methyl-orange from aqueous solution. J. Solid State Chem. 2017, 255, 157-166. [CrossRef]

69. Nazir, M.A.; Khan, N.A.; Cheng, C.; Shah, S.S.A.; Najam, T.; Arshad, M.; Sharif, A.; Akhtar, S.; Rehman, A.u. Surface induced growth of ZIF-67 at Co-layered double hydroxide: Removal of methylene blue and methyl orange from water. Appl. Clay Sci. 2020, 190, 105564-105572. [CrossRef]

70. Huang, L.; He, M.; Chen, B.; Hu, B. Magnetic Zr-MOFs nanocomposites for rapid removal of heavy metal ions and dyes from water. Chemosphere 2018, 199, 435-444. [CrossRef]

71. KarzarJeddi, M.; Laitinen, O.; Mahkam, M.; Liimatainen, H. Zwitterionic hybrid aerobeads of binary metal organic frameworks and cellulose nanofibers for removal anionic pollutants. Mater. Des. 2020, 196, 109106. [CrossRef]

72. He, Y.; Li, H.; Zhou, L.; Xu, T.; Peng, C.J.; Liu, H.L. Removal of methyl orange from aqueous solutions by a novel Hyper-crosslinked aromatic triazine porous polymer. Acta Phys. Chim. Sin. 2019, 35, 299-306. [CrossRef]

73. Liu, L.; Ge, J.; Yang, L.; Jiang, X.; Qiu, L. Facile preparation of chitosan enwrapping $\mathrm{Fe}_{3} \mathrm{O}_{4}$ nanoparticles and MIL-101(Cr) magnetic composites for enhanced methyl orange adsorption. J. Porous Mater. 2016, 23, 1363-1372. [CrossRef]

74. Xu, W.; Li, W.; Lu, L.; Zhang, W.; Kang, J.; Li, B. Morphology-control of metal-organic framework crystal for effective removal of dyes from water. J. Solid State Chem. 2019, 279, 120950. [CrossRef]

75. Zhang, X.; Qian, L.; Yang, S.; Peng, Y.; Xiong, B.; Li, J.; Fang, P.; He, C. Comparative studies of methyl orange adsorption in various metal-organic frameworks by nitrogen adsorption and positron annihilation lifetime spectroscopy. Microporous Mesoporous Mater. 2020, 296, 109993. [CrossRef]

76. Shen, T.; Luo, J.; Zhang, S.; Luo, X. Hierarchically mesostructured MIL-101 metal-organic frameworks with different mineralizing agents for adsorptive removal of methyl orange and methylene blue from aqueous solution. J. Environ. Chem. Eng. 2015, 3 , 1372-1383. [CrossRef]

77. Hou, P.; Xing, G.; Han, D.; Zhao, Y.; Zhang, G.; Wang, H.; Zhao, C.; Yu, C. MIL-101(Cr)/graphene hybrid aerogel used as a highly effective adsorbent for wastewater purification. J. Porous Mater. 2019, 26, 1607-1618. [CrossRef]

78. Vo, T.K.; Trinh, T.P.; Nguyen, V.C.; Kim, J. Facile synthesis of graphite oxide/MIL-101(Cr) hybrid composites for enhanced adsorption performance towards industrial toxic dyes. J. Ind. Eng. Chem. 2021, 95, 224-234. [CrossRef] 